\title{
As Repercussões Bio-Psíquicas do Parto Humanizado Sob a Lógica da Mulher
}

\author{
The Bio-Psychic Repercussions of Humanized Childbirth Under the Logic of Women
}

\section{Las repercusiones biopsíquicas del parto humanizado bajo la lógica de la mujer}

\section{Larissa de Medeiros Duque ${ }^{*}$, Geísa Sereno Velloso da Silva ${ }^{2}$, Jannaína Sther Leito Godinho Silva ${ }^{3}$, Manoela Alves $^{4}$, Eliara Adelino da Silva ${ }^{5}$, Elisângela Nascimento Fernandes Gomes ${ }^{6}$}

Como citar esse artigo. Duque, LM; da Silva, GSV; Silva, JSLG; Alves, M; da Silva EA; Gomes, ENF. As Repercussões Bio-Psíquicas do Parto Humanizado Sob a Lógica da Mulher. Revista Pró-UniverSUS. 2021 Jul./Dez.; 12 (2)SUPLEMENTO: $15-20$

\section{Resumo}

O parto humanizado traz como um dos seus objetivos a contemplação de todos os direitos da parturiente, desde a descoberta de sua gestação até o momento definitivo do parto. Trata-se de uma revisão integrativa que busca evidenciar a perspectiva da mulher sobre os benefícios do parto humanizado. A humanização do parto coloca a mulher como protagonista de todas as suas escolhas e dá a ela o direito de opinar sobre os detalhes que promovam a ela maior bem-estar físico e emocional. Constatou-se através deste estudo que muitos avanços ainda hão de ser feitos no campo de humanização do parto.

Palavras-chave: Parto; Humanização, Enfermagem, Relação Enfermeiro-Paciente.

\begin{abstract}
The humanized birth brings as one of its objectives the contemplation of all rights of the mother, since the discovery of her pregnancy until the final delivery time. This is an integrative review that seeks to highlight the woman's perspective on the benefits of humanized birth. The humanization of childbirth puts women as the protagonist of all her choices and gives it the right to give an opinion on the details to promote her physical and emotional well-being. It was found by this study that many further advances are to be made in the humanization of delivery field.

Keywords: Childbirth; Humanization, Nursing, Nurse-Patient Relationship.

\section{Resumen}

El parto humanizado trae como uno de sus objetivos la contemplación de todos los derechos de la parturienta, desde el descubrimiento de su embarazo hasta el momento definitivo del parto. Se trata de una revisión integradora que busca resaltar la perspectiva de la mujer sobre los beneficios del parto humanizado. La humanización del parto coloca a la mujer como protagonista de todas sus elecciones y le da derecho a opinar sobre los detalles que promueven su mayor bienestar físico y emocional. A través de este estudio se encontró que aún quedan muchos avances por hacer en el campo de la humanización del parto.

Palabras clave: Parto; Humanización, Enfermería, Relación Enfermera-Paciente.
\end{abstract}

Afiliação dos autores: ${ }^{1 *}$ Acadêmica do Curso de Enfermagem, Universidade de Vassouras. RJ, Brasil. ORCID: https://orcid.org/0000-0001-6519-5871

${ }_{2}^{2}$ Mestre em Enfermagem pela UFRJ, Docente do Curso de Enfermagem da Universidade de Vassouras, Vassouras, RJ, Brasil. ORCID: https://orcid.org/0000-0003-0304-8010.

${ }^{3}$ Mestre em Enfermagem pela Universidade Federal Fluminense, Docente do Curso de Enfermagem da Universidade de Vassouras. Vassouras, RJ, Br ORCID: https://orcid.org/00000002-8308-2093.

${ }^{4}$ Mestre em Enfermagem. Docente do curso de Enfermagem, Universidade de Vassouras. RJ, Brasil. ORCID: https://orcid.org/0000-0003-4239-9577.

${ }^{5}$ Mestre em Ciências da Saúde e Meio Ambiente, Docente do Curso de Enfermagem da Universidade de Vassouras, Vassouras, RJ, Brasil. ORCID: https://orcid.org/0000-0003-43876662.

${ }^{6}$ Mestre em Ciências Ambientais pela Universidade de Vassouras, Docente do Curso de Enfermagem da Universidade de Vassouras, Vassouras, RJ, Brasil. ORCID: http://orcid. org/0000-0001-8432-4157.

* Email de correspondencia: larissamed96@hotmail.com

Recebido em: 22/01/21. Aceito em: 25/05/21 


\section{Introdução}

O parto humanizado traz como um dos seus objetivos a contemplação de todos os direitos da parturiente, desde a descoberta de sua gestação, que incluí os momentos de planejamento de parto durante as consultas pré-natais até o momento definitivo do parto, onde todo esse planejamento deve, se possível, ser colocado em prática de maneira integral desde que não coloque a vida da parturiente e seu bebê em risco. A humanização do parto é um processo importante e constante que acontece em todas as esferas de atendimento tanto na rede pública quanto privada dos serviços de saúde no Brasil, pois, diariamente a mulher possuí seus direitos de parir com humanização violados através atos como violência verbal, físico através de procedimentos realizados de maneira incorretas ou desnecessária entre inúmeros outros ${ }^{1}$.

A humanização do parto coloca a mulher como protagonista de todas as suas escolhas e dá a ela o direito de não só escolher o local, como também escolhe o seu acompanhante, e opinar sobre os detalhes que possam promover a ela maior bem-estar físico e emocional durante todo o processo. Respeitando assim, o processo natural e fisiológico do parto fazendo com que as condutas desnecessárias, ou de risco sejam evitadas. Inclusive, ele segue as recomendações que a Organização Mundial da Saúde recomenda ${ }^{3}$.

E muito importante que se crie um ambiente acolhedor que torne essa experiência segura e agradável, se for do desejo com a presença de um acompanhante para torna esse momento mais especial para a mulher e para o seu bebê. Deve-se atentar para os aspectos culturais, psíquicos e espirituais que estão envolvidos no parto. A mulher deve estar ciente de cada procedimento que será ser realizado durante o seu trabalho. E que seja realizado de forma que respeite suas escolhas e seus direitos promovendo assim uma assistência segura e integral ${ }^{3}$.

\section{Metodologia}

Trata-se de uma revisão integrativa que busca evidenciar a visão de diversos autores que enfoquem na perspectiva da mulher sobre os benefícios do parto humanizado, a revisão integrativa é um método de pesquisa que, nos últimos anos, tem vindo a ser utilizado na área da saúde e tem permitido dar visibilidade à contribuição da Enfermagem para a melhoria da prestação de cuidados. É denominada integrativa porque fornece informações amplas sobre um assunto/ problema, constituindo, assim, um abrangente corpo de conhecimento, de rigor metodológico ${ }^{4}$.

O levantamento de artigos para o presente estudo ocorreu através de uma busca em bases científicas como a Biblioteca Virtual em Saúde (BVS), Literatura Latino-Americana e do Caribe em Ciências da Saúde (LILACS), Scientific Library Eltronic Online (SciELO), Resvista Pró-univerSUS.

As buscas foram realizadas com os descritores, Assistência em Enfermagem, Parto Humanizado, Empoderamento Para a Saúde, Gravidez.

Os critérios de inclusão dos artigos foram, artigos públicados em revistas e períodicos científicos, publicados entre os anos de 2015 e 2020, com texto completo e em português, que abordem a perspectiva da mulher no processo de gestação e parto.

No que tange aos critérios de exclusão, foram descartados artigos fora do recorte temporal, que não possuíssem texto completo em português e se encontrasse somento em inglês, duplicados em bases de dados e que não se adequassem a temática do estudo.

Com isso, em uma busca primária foram encontrados 841 artigos distribuídos pelas bases de dados científicos da seguinte forma: BDENF - 400, Lilacs - 360, IBECS - 9, SciELO - 72, que foram tratados seguindo os critérios de inclusão e exclusão.

Após uma exclusão primária identificou-se 301 artigos distribuídos da seguinte forma: BDENF - 168, Lilacs - 125, IBECS - 3, SciELO - 5, Por fim após leitura dos títulos foram selecionados 36 artigos para leitura na íntegra e destes, 16 foram incluídos ao presente artigo.
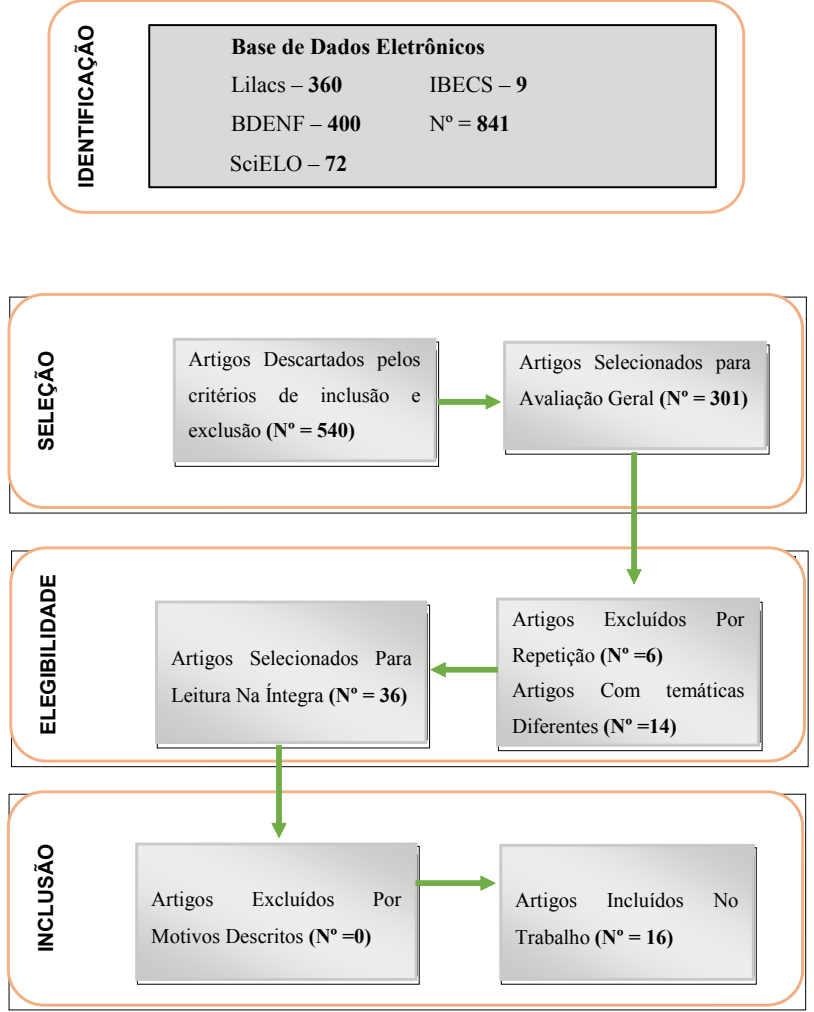

Figura 1. Fluxograma.

Fonte: Os autores (2021). 


\section{Resultados e Discussão}

\section{Humanização do parto e nascimento: visão dos profissionais de saúde}

O termo humanização vem aparecendo na primeira década do século XXI com bastante frequência na literatura de saúde, e isso parece ser uma consequência das recentes recomendações do Ministério da Saúde que propõe uma Política Nacional de Humanização ${ }^{5}$.

$\mathrm{O}$ autor ${ }^{6}$ ressalta que o acesso à informação e uma relação interpessoal acolhedora transmitem à mulher sentimentos positivos e geram um ambiente seguro para a parturição, o modelo humanizado privilegia o bem-estar da mulher e de seu bebê, buscando ser o menos invasivo possível, considerando tanto os processos fisiológicos, quanto os psicológicos e o contexto sociocultural, faz uso da tecnologia de forma apropriada, sendo que a assistência se caracteriza pelo acompanhamento contínuo do processo de parturição, garante às mulheres e às crianças vivenciar a experiência da gravidez, do parto e do nascimento com segurança.

As ações de educação em saúde dos profissionais de saúde para humanização do parto foram identificadas como a apresentação do local de permanência da mulher do momento de admissão em pré-parto ao puerpério; Orientações a respeito da liberdade de escolha, tanto em relação ao local quanto à posição; escolha do tipo de parto e cuidado e conforto nos momentos que antecedem o nascimento e disponibilidade para o esclarecimento de dúvidas da gestante ${ }^{7}$.

A humanização durante o trabalho de parto tem como objetivo promover o nascimento saudável e prevenir a morbimortalidade materna e perinatal pois o enfermeiro deve estabelecer uma boa relação com a mulher antes mesmo do trabalho de parto, no momento do seu pré-natal no qual é criado as primeiras relações entre profissional e a mulher, pois trata-se de um momento muito especial na vida da mulher e de sua família.

Respeitando os direitos, cultura e necessidade promovendo assim um atendimento de qualidade, integral e individualizado preservando a privacidade e autonomia da mulher, evitando-se intervenções desnecessárias por parte da equipe de saúde ${ }^{7}$.

O primeiro modelo de plano de parto foi elaborado por Sheila Kitzinger, em 1980, nos Estados Unidos, e defendia que o parto é um processo fisiológico que grande parte das mulheres passaria ao longo de suas vidas e que não pode ser encarado como patológico e ser medicado, como tinha acontecido ao longo dos anos devido à inclusão do parto no ambiente hospitalar. Com a intenção de proporcionar maior autonomia às mulheres e reduzir intervenções desnecessárias, os países anglo- saxônicos começaram a utilizar o plano de parto9 .

Para os autores ${ }^{11}$. O plano de parto é um documento, de caráter legal, escrito pelas mulheres grávidas após receberem informações sobre a gravidez e o processo de parto, considerando seus valores e desejos pessoais, além das expectativas criadas sobre seu parto ao longo da gravidez. O PP é o eixo da relação clínica estabelecida entre as mulheres grávidas e o/a profissional e pode servir para orientar a atenção de saúde prestada ao longo de todo o processo ${ }^{6}$.

A Organização Mundial de Saúde - OMS argumenta que o parto humanizado tem início no prénatal com o aconselhamento e explicação do processo gravídico-puerperal, considerando as necessidades da mulher na admissão e no parto; devem-se respeitar suas individualidades e desejos; durante o trabalho de parto dar liberdade de escolher a posição mais apropriada e agradável para parir, monitorar seu estado e do bebê e, após o parto, prestar os cuidados à puérpera e ao bebê3.

De acordo com o Ministério da Saúde, um parto humanizado requer a criação um ambiente acolhedor e a inclusão de procedimentos hospitalares que rompam com o tradicional isolamento imposto à mulher que vai ter um filho. Por isso, o órgão considera que, para haver uma assistência humanizada, é necessária uma atitude ética e solidária por parte dos profissionais de saúde. A Organização Mundial da Saúde (OMS) criou, em 2000, um guia com as recomendações para uma experiência de parto positiva. Em fevereiro de 2018, elas foram atualizadas. Esse guia reúne as práticas recomendadas, as que não devem ser feitas e as que podem acontecer sob circunstâncias específicas durante o pré-natal, o trabalho de parto e os cuidados logo após o nascimento ${ }^{3}$.

O ambiente deve ser preparado previamente para garantir o direito à privacidade, à presença de um acompanhante, e a segurança física e emocional. Os profissionais de saúde devem também oferecer o apoio empático e as informações e explicações que a mulher e seu acompanhante solicitarem ${ }^{13}$.

\section{Os direitos da mulher durante o trabalho de parto}

Extrai-se do texto legal que "Toda gestante tem direito a receber assistência médica humanizada durante o parto nos estabelecimentos públicos de saúde". O parto humanizado possui três princípios: a segurança, transparência e pouca invasão. Segundo a lei 15.759, podemos refletir que ela ressalta o direito que a mulher tem de receber uma assistência humanizada durante todo o processo do seu trabalho de parto ${ }^{14}$.

Dispõe Sobre Assegura o direito ao parto humanizado nos estabelecimentos públicos de saúde do Estado e dá outras providências). Destaca-se que os profissionais de saúde devem oferecer a mulher uma experiência única com um atendimento digno e de qualidade oferecendo um ambiente acolhedor, com 
atitudes éticas e solidárias visando evidenciar a mulher como protagonista do seu parto ${ }^{14,3}$.

$\mathrm{O}$ enfermeiro deve enfatizar a mulher sobre a importância de um acompanhante durante o trabalho de parto, esta pessoa deve ser escolhida pela mulher, e deve ser de sua confiança para que a mesma se sinta segura e receba todo o apoio que precisa durante todo o processo do trabalho de parto. Deve-se incentivar a mulher sobre o seu acompanhante desde suas consultas de pré-natal pois assim garante que esta pessoa estará capacitada e habilitada para oferecer todo apoio necessário a mulher.

A autora ${ }^{8}$ traz a interessante perspectiva do empoderamento da mulher sobre o conhecimento de seus direito como um mecanismo de humanização do parto, pois, através do conhecimento do que pode ou não ser feito ela terá total autonomia de decisão e participação do seu plano de parto, desde que este prossiga sem gerar riscos a saúde fetal ou da gestante.

No Brasil, o Ministério da Saúde afirma que a presença de uma pessoa durante todo o processo parturitivo é um dos direitos da mulher. Recomendase, então, que o acompanhante seja de livre escolha da gestante, contribuindo para uma melhor repercussão para binômio mãe e recém-nascido, possibilitando um suporte emocional e segurança ${ }^{3}$.

No processo de internação da mulher ela se sente inseguras pois ela saiu de um ambiente acolhedor, onde ela se sente protegida e segura pelos seus familiares e vai para um local desconhecido para ela que é o hospital, tendo que dividir o seu espaço com outras parturientes e profissionais que ela desconhece, portanto, $\operatorname{para}^{15} \mathrm{a}$ presença do acompanhante durante todo o processo é de extrema importância para promover segurança e conforto, além de ser um facilitador a parturição em si. Por isso devemos oferecer a ela um ambiente acolhedor que seja confortável, prestar uma assistência de qualidade presando sua tranquilidade e relaxamento tanto da mulher quanto do seu companheiro e dos profissionais de saúde ${ }^{16}$.

\section{O cuidado na promoção do planejamento do parto}

O Plano de Parto é a primeira de uma série de recomendações da Organização Mundial da Saúde (OMS) denominadas "Boas Práticas de Atenção ao Parto e Nascimento" e preconizadas desde 1996, com o intuito de reorganizar e humanizar a assistência obstétrica em todo o mundo ${ }^{13}$.

Devemos esclarecer para gestante sobre a fisiologia do trabalho de parto, dúvidas, dar a ela a possibilidade de escolha de métodos não farmacológicos para o alívio da dor e os riscos de intervenções desnecessárias e fornecer a ela todas informações e orientações necessárias.

A importância do Plano de Parto está condicionada ao princípio bioético da autonomia e empoderamento, uma vez que se encontra em uma posição evidenciada dentre as condutas que devem ser estimuladas durante a gestação pela OMS. O Plano de parto deve ser construído pela gestante em conjunto com os enfermeiros da Atenção Primária de Saúde, e discutido com os profissionais que irão realizar o atendimento hospitalar ${ }^{17}$.

Para as autoras ${ }^{18,19}$ o plano de parto deve ser feito durante o pré-natal com a mulher e com o seu acompanhante de escolha dela, porém, a violência obstétrica ainda é um problema recorrente por parte da equipe de saúde e, está por sua vez, é caracterizada de várias formas como, agressões verbais, procedimentos desnecessários e o principal fator que abordamos, o desrespeito a autonomia da paciente.

Além de ${ }^{18}$ citar inúmeras outras violências, a privação do acompanhante na sala de parto é outro grande problema enfrentado com frequência, já que durante esse processo a mulher sente-se muito vulnerável e exposta, então como medida a ser tomada $\mathrm{a}^{13}$ Criou um guia de ações e medidas com o intuito de auxiliar na diminuição dessas medidas contando também, posteriormente com o projeto de lei $\mathrm{n}^{\mathrm{o}} 11.10^{20}$.

Por sua vez 0 autor ${ }^{21}$ trata atuação do parceiro neste momento como algo primordial e de grande relevância para que o progresso do nascimento possa ocorrer de forma fisiológica, este fato é comprovado por estudos que certificam se de que no tempo do trabalho de parto a presença de uma companhia masculina propicia melhores condições físicas e psíquicas para a gestante, sendo assim, o acompanhante que participa das consultas de pré-natal pode oferecer maior apoio à mulher em vista do nascimento de seu filho, fazendo com que a sua satisfação com esse evento seja ainda maior.

Para as autoras ${ }^{5.22}$ preocupações no processo de parto da primípara incluem o medo de ocorrer algo de errado, de gerar um natimorto e com sua própria saúde, enquanto que, as multíparas podem temer o caminho percorrido até o nascimento já que podem possuir uma experiência prévia com muitas dores, iatrogenias, violências obstétricas e ficam temerosas que aquela situação se repita.

Segundo nota publicada por $^{1}$ e o autor ${ }^{23}$ boas práticas através de massagem para alívio da dor, utilizados durante o trabalho de parto, são tecnologias de cuidado que envolve conhecimentos estruturados quanto ao desenvolvimento da prática de enfermagem em centro obstétrico. Essa prática tem sido introduzida em algumas maternidades brasileiras a partir da década de 90, com o movimento de humanização do nascimento e com as recomendações do Ministério da Saúde (MS) para assistência ao parto. 


\section{Conclusão}

Constatou-se através deste estudo que muitos avanços ainda hão de ser feitos no campo de humanização do parto em todas as suas fases, seja no pré natal ou no momento de concepção, além da evidente necessidade de mais profissionais capacitados para este campo de atuação da enfermagem evidenciou-se que o empoderamento da mulher através da informação dos seus direito é pouco difundida durante o planejamento do parto, desde a escolha do acompanhante que deve ser criteriosa até o tipo de parto desejado seguindo as recomendações dos profissionais também envolvidos neste processo.

Podemos ainda expandir os alvos desta informação para o acompanhante, para que este seja capaz de entender e exercer seu tão importante papel neste processo que é o de confortar, auxiliar e assegurar que a parturiente tenha seu direito de escolha contemplado. Além de atuar na diminuição da tensão em um momento de vúlnerabilidade da parturiente, propciando através de sua presença e conhecimentos um ambiente mais confortável e seguro para a mesma.

Fica claro o papel do enfermeiro como peça fundamental durante todo esse processo, pois, o mesmo mantém um vínculo com a parturiente durante o processo desde a concepção até o nascimento ele é o profissional que serve de ponte e assegura o recebimento de todas estas informações, é aquele que as esclarece.

\section{Referências}

1. OMS. Organização Pan-Americana da Saúde. Mulheres grávidas devem ter acesso aos cuidados adequados no momento certo, afirma OMS, 2016. Acesso em: 15/01/2021. Disponível em: https://www.paho. org/bra/index.php?option=com_content\&view=article\&id=5288:mulhere s-gravidas-devem-ter-acesso-aos-cuidados-adequados-no-momento-certoafirma-oms \&Itemid=820

2. Brasil, Minietério da Saúde. Projeto de lei $n^{0} 712 / 13$, do Deputado Carlos Bezerra Jr - PSDB) Assegura o direito ao parto humanizado nos estabelecimentos públicos de saúde do Estado e dá outras providências, 2013. Acesso em: 18/12/2020. Disponível em: https://www.al.sp.gov.br/ propositura/?id=1161364

3. OMS, Organização Mundial de Saúde. Informes técnicos, recomendações para estabelecer padrão de cuidado para mulheres grávidas e reduzir intervenções médicas desnecessárias, 2018. Acesso em: 12/01/2021. Disponível em: https:/www.sns.gov.pt/noticias/2018/02/20/parto-novasrecomendacoes-da-oms/.

4. De Sousa, Luís Manuel Mota et al. A metodologia de revisão integrativa da literatura em enfermagem. N²1 Série 2-Novembro 2017, p. 17, 2017.Acesso em 20/12/2020. Disponível: http://www.sinaisvitais.pt/ images/stories/Rie/RIE21.pdf\#page $=17$

5. Brasil. Ministério da Saúde. Secretaria de Atenção à Saúde. Núcleo Técnico da Política Nacional de Humanização. HumanizaSUS: documento base para gestores e trabalhadores do SUS. 3a ed. Brasília: Ministério da Saúde; 2006. Acesso em: 20/01/2021. Disponível em: https://bvsms.saude. gov.br/bvs/publicacoes/documento base.pdf

6. Balaskas J. Parto ativo: guia prático para o parto natural (A história e a filosofia de uma revolução). São Paulo: Aquariana. 2016. Acesso em $19 / 12 / 2020$
7. Veloso ACF, Silva LSRD, Barros PGD, Gomes RRT, Santos ASD, Oliveira HMDS. Atuação dos profissionais de saúde e o processo de humanização no centro obstétrico. Nursing (Säo Paulo), 2020; 4570-4579. Acesso em 18/12/2020. Disponível em: https://www.researchgate.net/ profile/Liniker_Silva2/publication/344558771 Atuacao dos profissionais de saude e o processo de humanizacao no centro obstetrico/

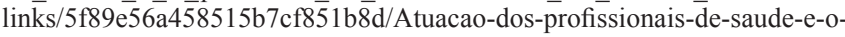
processo-de-humanizacao-no-centro-obstetrico.pdf

8. do Nascimento Freire L, da Silva GSV. A falta do protagonismo da mulher no trabalho de parto-parto e nascimento. Revista Pró-UniverSUS, 2019; 10(1), 34-37.Acesso em 15/01/2021 Disponivél em: http://editora. universidadedevassouras.edu.br/index.php/RPU/article/view/1608

9. Chacham AS, Perpétuo IHO. Determinantes sócio-econômicos da incidência de partos cirúrgicos em Belo Horizonte. In: Anais do X Encontro Nacional de Estudos Populacionais. Belo Horizonte: Associação Brasileira de Estudos Populacionais; 1996. p. 2587-610.Acesso em 19/12/2020. Disponível em: http://www.abep.org.br/publicacoes/index.php/anais/article/ view/828

10. Pereira CCC, Buttow LJR, Cremonese L, Rampelloto GF, Wilhelm LA, Barreto C. N. Contribuições do plano de parto e estratégias para inserção no pré-natal: revisão narrativa. Disciplinarum Scientia| Saúde, 2020; 21(2), 59-71.Acesso em 28/12/2020. Disponível em: https://periodicos.ufn.edu.br/ index.php/disciplinarumS/article/view/3218

11. Santos FSDR, Souza PAD, Lansky S, Oliveira BJD, Matozinhos FP, Abreu ALN, Pena ÉD. Os significados e sentidos do plano de parto para as mulheres que participaram da Exposição Sentidos do Nascer. Cadernos de Saúde Pública, 2019; 35, e00143718.Acesso em 15/01/2021. Disponível em: https://www.scielosp.org/article/csp/2019.v35n6/e00143718/

12. Suárez-Cortés $\mathrm{M}$, Armero-Barranco D, Can - teras-Jordana $\mathrm{M}$, Martínez-Roche ME. Uso e influência de los planes de parto y nacimiento en el proceso de parto humanizado. Rev Lati - noam Enferm 2015; 23:520-6.) Acesso em 27/12/2020. Disponível em https://www.scielo.br/scielo.php?pid $=\mathrm{S} 010411692015000300520 \&$ script $=$ sci_arttext \&tlng $=\mathrm{es}$

13. OMS, Organização Mundial da Saúde (CH). Saúde Reprodutiva e da Família. Saúde Materna e Neonatal. Unidade de Maternidade Segura. Assistência ao parto normal: um guia prático: relatório de um grupo técnico. Genebra: OMS; 1996). Acesso em: 18/12/2020. Disponível em: https:// pesquisa.bvsalud.org/bvsms/resource/pt/mis-9570

14. Governo do Estado de São Paulo. Diário Oficial. Sessão 1. Lei $\mathrm{n}^{\circ} 15.759$ de 25 de março de 2015 .

15. Gianini SOLP, da Silva GSV.A presença do acompanhante no trabalho de parto, parto e pós-parto: compreensão das gestantes. Revista Pró-UniverSUS, 2020; 11(1), 21-26. Acesso em 27/12/2020. Disponível em: http://editora.universidadedevassouras.edu.br/index.php/RPU/article/ view/2099

16. Santos ALS, de Oliveira ARS, AmorimT, da Silva UL. O acompanhante no trabalho de parto sob a perspectiva da puérpera. Revista de Enfermagem da UFSM, 2015;5(3), 531-539. Acesso em 01/01/2021. Disponível em: http://cascavel.ufsm.br/revistas/ojs-2.2.2/index.php/reufsm/ article/view/17337

17. Medeiros RMK et al. Repercussões da utilização do plano de parto no processo de parturição. Revista Gaúcha de Enfermagem. 2019; 40(20): 180233, 2019.) Acesso em 28/12/2020. Disponível em: https://www.scielo.br/ scielo.php?pid=S1983-14472019000100504\&script=sci_abstract\&tlng=es

18. Miranda FL, Velloso GS, de Oliveira Lima P, Rangel SC, de Almeida HF, Pinheiro MLP, Costa LNV. Violência obstétrica: percepções de enfermeiros obstétricos em uma maternidade de Minas Gerais. HU Revista 2019;45(4), 415-420.Acesso em 06/12/2020. Disponível em: https:// periodicos.ufjf.br/index.php/hurevista/article/view/27818

19. Paula E, Alves VH, Rodrigues DP, Felicio FC, Araújo RCB, Chamilco RASI, Almeida VLM. Violência obstétrica e o atual modelo obstétrico, na percepcão dos gestores em saúde. Texto Contexto Enferm, 2020.Acesso em 06/12/2020. Disponível em: https://www.scielo.br/scielo.php?pid=S010321 $002020000100473 \&$ script $=$ sci arttext

20. Brasil \& Brasil. (2005). Lei $n^{\circ} 11.108$, de 7 de abril de 2005. Altera a Lei ${ }^{\circ} 8.080$, de 19 de setembro de 1990, para garantir às parturientes o direito à presença de acompanhante durante o trabalho de parto, parto e pósparto imediato, no âmbito do Sistema Único de Saúde (SUS). Diário Oficial da União. Acesso em: 11/01/2021. Disponível em http://www.planalto.gov. 
br/ccivil_03/_ato2004-2006/2005/lei/111108.htm

21. Souza SRRK, Gualda DMR. A experiência da mulher e de seu acompanhante no parto em uma maternidade pública. Texto \& ContextoEnfermagem, 2016;25(1). Acesso em 15/12/2020. Disponível em: https:// www.scielo.br/scielo.php?pid=S010407072016000100309\&script $=$ sci arttext\&tlng=pt

22. De Almeida RDSS, de Oliveira RK, Gomes MFP, Fracolli, LA. Puerperal women's experiences regarding the nursing team performance during labor/Vivências de puérperas frente à atuação da equipe de enfermagem durante o trabalho de parto. Revista de Pesquisa: Cuidado é Fundamental Online, 2020;12, 345-349.Aceeso em 15/12-2020. Disponível em: http:// www.seer.unirio.br/index.php/cuidadofundamental/article/download/7117/

23. Bastos M. Atuação do enfermeiro obstetra na prática de relaxamento na sala de parto. Monografia. Curso de Especialização em Enfermagem Obstétrica - Rede Cegonha, Escola de Enfermagem. Universidade Federal de Minas Gerais, UFMG. 2015. Acesso em 28/12/2020. Disponível em: https:// repositorio.ufmg.br/handle/1843/33698 